\title{
First record of the cicada genus Semia Matsumura (Hemiptera, Cicadidae) from Vietnam, with the description of one new species and a key to species
}

\author{
Hong-Thai Pham ${ }^{1,3, \dagger}$, Masami Hayashi ${ }^{2, \ddagger}$, Jeng-Tze Yang ${ }^{3, \S}$
}

I Department of Insect Systematics, Institute of Ecology and Biological Resources (IEBR), 18 Hoang Quoc Viet St, Hanoi, Vietnam 2 Department of Biology, Faculty of Education, Saitama University, Saitama 338-8570, Japan 3 Department of Entomology, National Chung Hsing University, Taichung 402, Taiwan, R. O.C.

† urn:lsid:zoobank.org:author:E34CB863-7E3B-4E8F-8738-B41C07D9F5F9

† urn:lsid:zoobank.org:author:C5AA9237-7C33-4279-8E64-AEEDE5A3DE72

§ urn:lsid:zoobank.org:author:436B49F0-1387-4BA8-B2AF-94BE44D87023

Corresponding author: Hong-Thai Pham (phamthai1976@yahoo.com)

Academic editor: M. Webb | Received 12 October 2011 | Accepted 24 February 2012 | Published 9 March 2012

urn:lsid:zoobank.org:pub:B458E039-E91D-4C13-B827-7163CB00E948

Citation: Pham H-T, Hayashi M, Yang J-T (2012) First record of the cicada genus Semia Matsumura (Hemiptera, Cicadidae) from Vietnam, with the description of one new species and a key to species. ZooKeys 174: 31-40. doi: $10.3897 /$ zookeys. 174.2242

\begin{abstract}
The first record of the genus Semia Matsumura (Cicadidae: Cicadinae, Cicadini) from Vietnam is presented. One new species, Semia spinosa sp. n., is described from southern Vietnam. Photos of the adult, illustrations of the male genitalia, a distribution map and biological data are provided. A key to the species of Semia based on the male adults is also given.
\end{abstract}

\section{Keywords}

New record genus, Semia spinosa, morphology, Cicadina, Auchenorrhyncha

\section{Introduction}

The cicada fauna of Vietnam has received little attention since the descriptions of Distant (1913a, b, 1917a, b). According to previous reports, 133 cicada species are known from Vietnam, representing 45 genera in all three subfamilies, Cicadinae, Cicadettinae and Tet- 
tigadinae (Lee (2008), Pham and Yang $(2009,2010)$ and Pham et al. (2010)). So far only two species of Semia have been described, S. watanabei (Matsumura, 1907), the type species, from Taiwan and S. klapperichi Jacobi, 1944, from Fukien Province, China. Here we describe a third species, Semia spinosa sp. n., from Dong Nai Province, southern Vietnam.

Semia is similar to Leptosemia Matsumura, 1917, Terpnosia Distant, 1892 and Euterpnosia Matsumura, 1917, but has a dentate lateral margin to the pronotum (Fig. 2A), transverse male opercula that are nearly contiguous with each other (Fig. 2B) and lacks a tooth-like projection laterally on the male $4^{\text {th }}$ abdominal segment (Lee and Hayashi 2003).

\section{Materials and methods}

Four males of the new species Semia spinosa sp. n., were collected from the Phu Ly, Ma Da-Vinh Cuu Nature reserve (NR), Vinh Cuu district, Dong Nai Province in southern Vietnam. The holotype and two paratypes are deposited in the Institute of Ecology and Biological Resources, Hanoi, Vietnam (IEBR), and one paratype in the Natural History Museum, London (BMNH).

Nomenclature for family, subfamily and tribal classification follows that of Moulds (2005) and Lee (2008). Morphological terminology follows that of Moulds (2005). The male genitalia of the holotype were examined and photographed using a dissecting microscope (Leica MZ7 5). A distribution map (Fig. 1) produced by the software CFF 2.0 (Barbier and Rasmont 2000), and photos of habitus are provided (Fig. 2).

\section{Taxonomy}

\section{Family Cicadidae Latrielle \\ Subfamily Cicadinae \\ Tribe Cicadini \\ Subtribe Cicadina}

Genus Semia Matsumura, 1917

http://species-id.net/wiki/Semia

Semia Matsumura, 1917: 195. Type species: Leptopsaltria watanabei Matsumura, 1907 (Formosa).

Diagnosis. Head nearly as wide as or slightly narrower than base of mesonotum; inner area of pronotum generally concolorous to outer dilatation; male abdomen cylindrical, much longer than distance from head to cruciform elevation and slightly widest across 4th abdominal segment and wider than base of mesonotum; male tymbal cover very small and semicircular, mostly exposing tymbal in dorsal view; male 8th abdominal 
tergum mostly covered with white powder; ovipositor not protruding beyond abdominal segment 9; male operculum scale-like, roundish, and not extending beyond 2nd abdominal sternum; wings hyaline; 6th apical cell of forewing about as long as or longer than twice of 5th apical cell in median length. Based on Lee and Hayashi (2003).

Distribution. China, Taiwan, Vietnam (Fig. 5).

Remarks. This genus is similar to Leptosemia, Terpnosia and Euterpnosia (see Introduction).

\section{Semia spinosa sp. $\mathrm{n}$.}

urn:Isid:zoobank.org:act:B8A6B87E-9A4A-484C-90DE-4C4F7CFB2D8D

http://species-id.net/wiki/Semia_spinosa

Figs 2, 3A-B, 6C

Etymology. The species name refers to morphological feature such as spinosa for the uncus spines

Material examined. Holotype ${ }^{\Uparrow}$ : VIETNAM [VC.Ho.0650, Phu Ly, Ma Da-Vinh

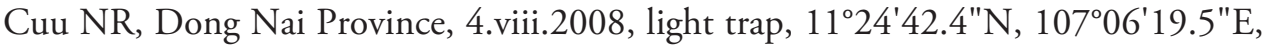
$100-150 \mathrm{~m}$, leg Hoang Vu Tru] (IEBR).

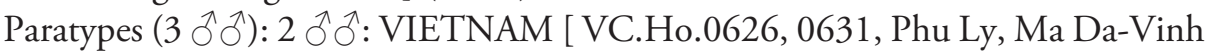
Cuu NR, Dong Nai Province, 31.vii.2008, 100-150m, leg Hoang Vu Tru] (IEBR);

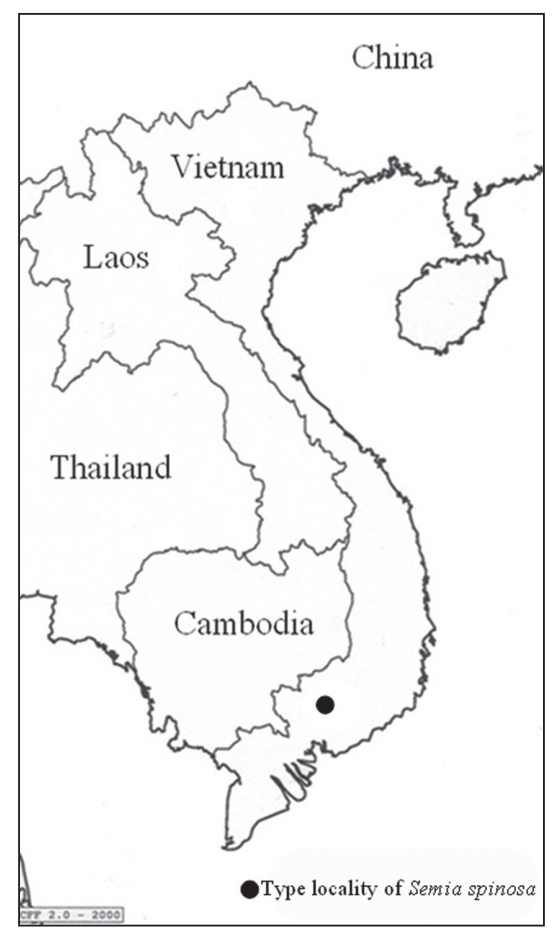

Figure I. Type locality of Semia spinosa sp. n.; (see text for further details). 


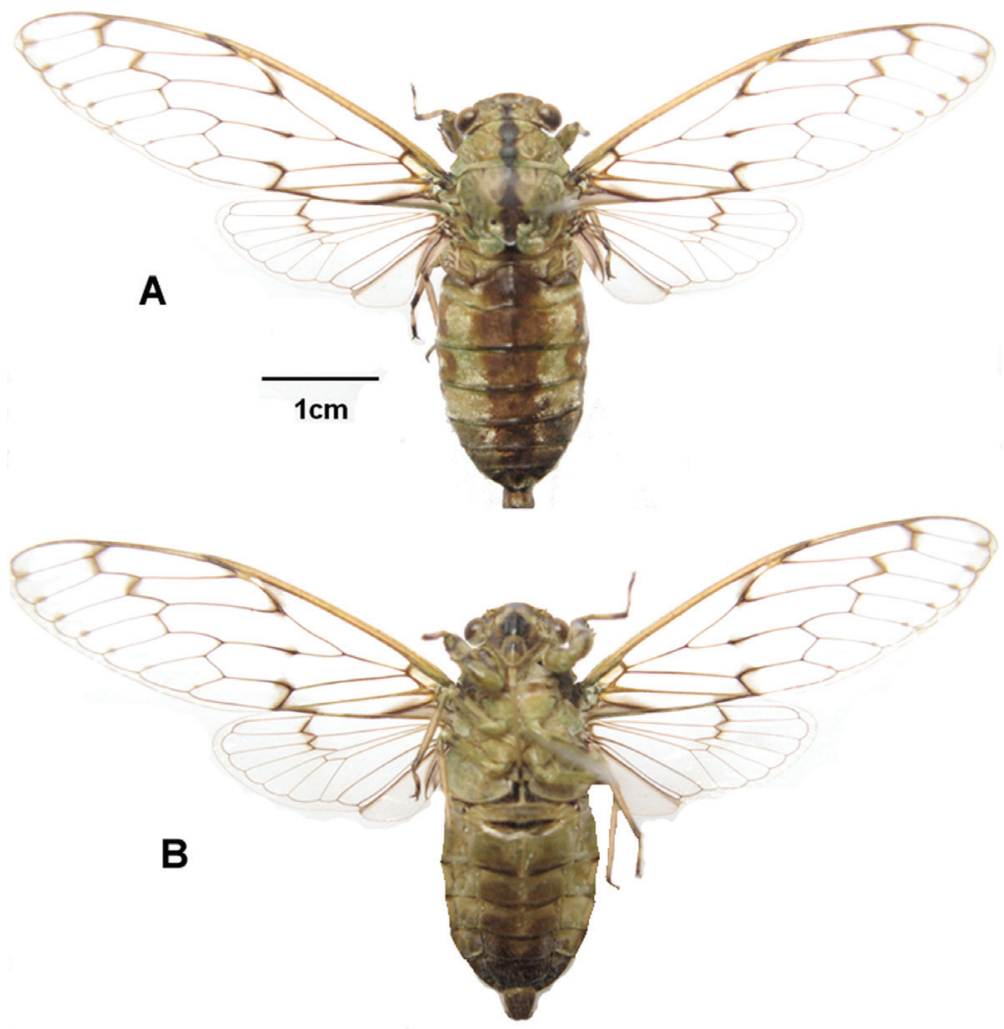

Figure 2. Semia spinosa sp. n. (male): A dorsal view B ventral view.

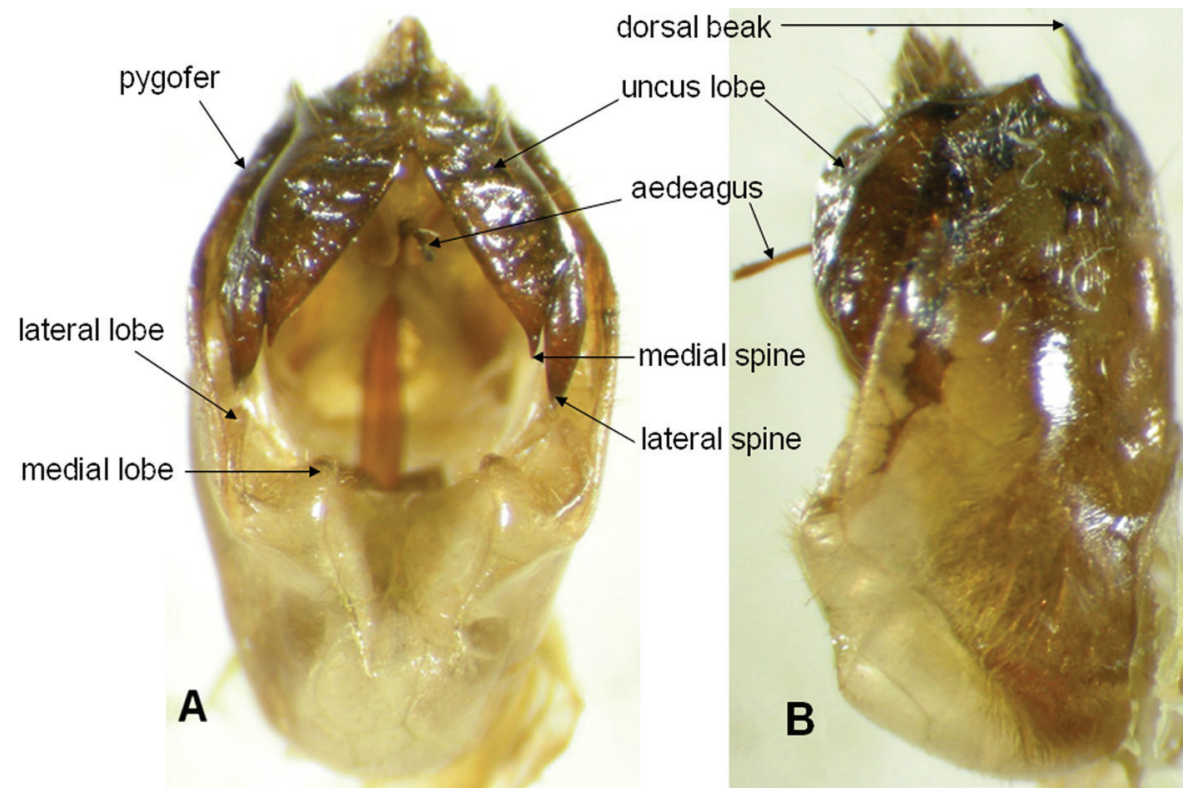

Figure 3. Male genital capsule of Semia spinosa sp. n.: A ventral view B lateral view. 


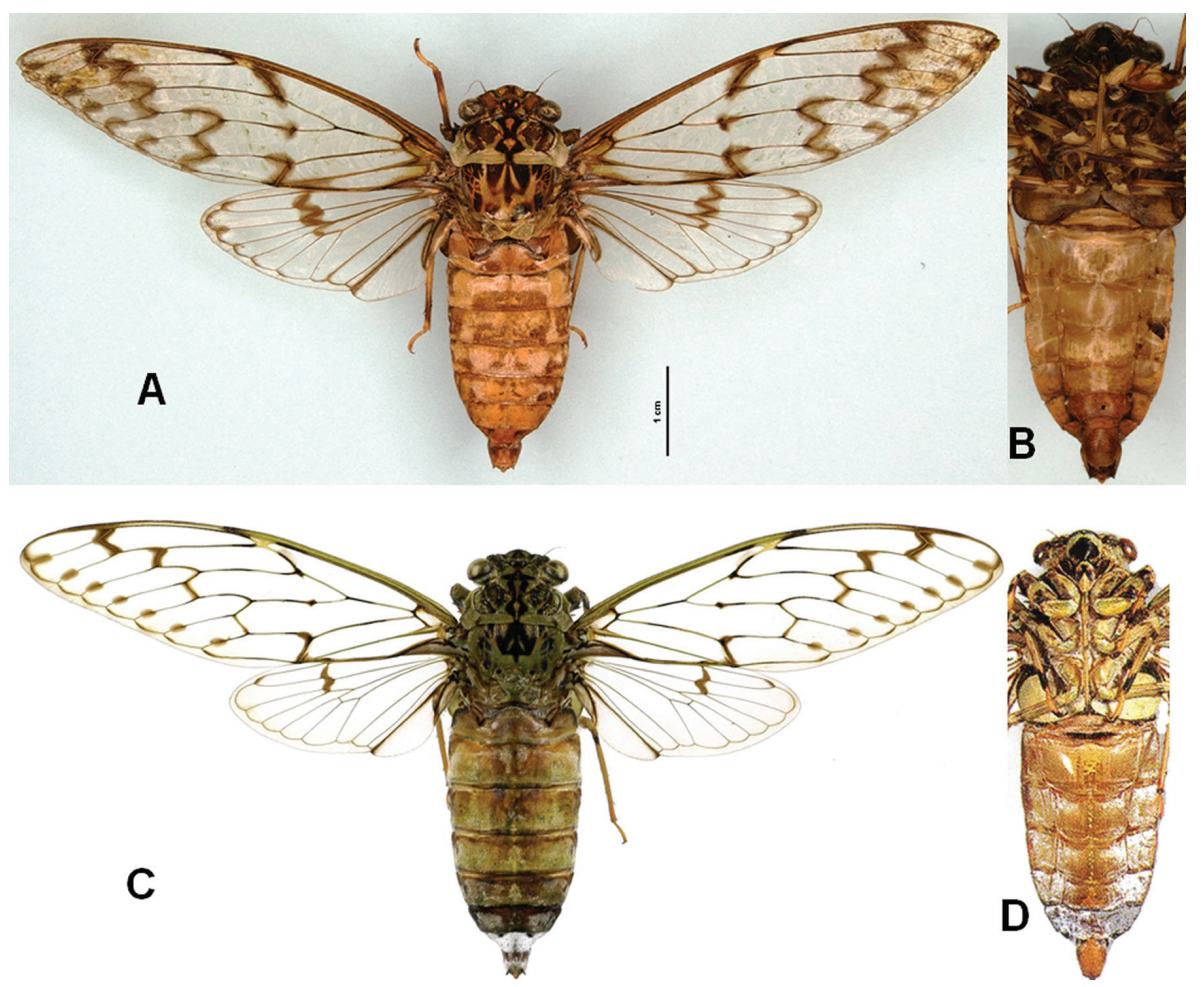

Figure 4. Semia species in dorsal view and ventral view (male): A, B S. klapperichi (photograph by Dirk Ahrens) C, D S. wantanabei (after Chen 2007).

1 ô: [VC.Ho.0765, Phu Ly, Ma Da-Vinh Cuu NR, Dong Nai Province, 2.viii.2008, light trap and netting, 100-150m, leg Ta Huy Thinh] (BMNH).

Description. Head (Figs 2A, 2B, 7, 8): head pale yellowish-brown with following markings: broad median longitudinal band on frons and supra-antennal plate, dark brown; postclypeus dorsally with two oblique oval dark brown patches, in facial view upper half with transverse brown bands, lower half blackish brown; lower half of anteclypeus blackish brown, area between eye and antenna on gena, lorum and apex of rostrum, dark brown. Head including eyes as wide as mesonotum at base; rostrum reaching posterior coxae.

Thorax (Figs 2A, 2B): pale yellowish-green, longitudinal broad band on pronotum narrowed centrally, longitudinal broad band on mesonotum, spot between submedian and lateral sigillae, scutal depression, two spots on lateral margin of mesonotum, central area of cruciform elevation, second anepisternum, anepimeron and katepisternum, dark brown. Pronotal collar with a small dentate projection.

Wings (Fig. 2A): fore and hind wings hyaline, with veins brown or fuscous, and costal margin tawny; fore wings slightly tinged and spotted with infuscations on most veins.

Legs (2B): pale yellow with markings as follows: fore leg with femur, tibia, metatarsus and pretarsus blackish brown, primary spine of femur dark brown, secondary spine 


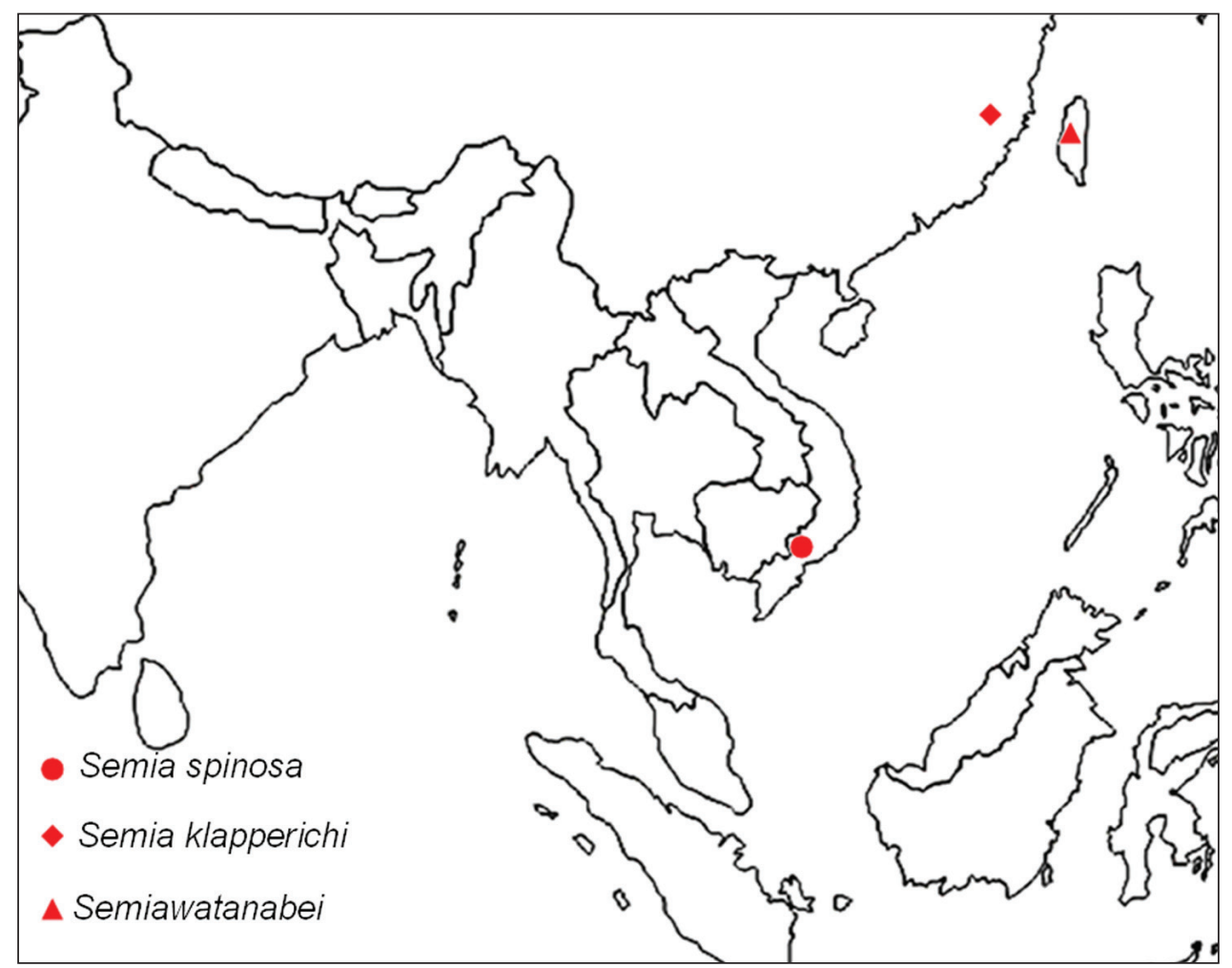

Figure 5. Distribution of the Semina species in the world.
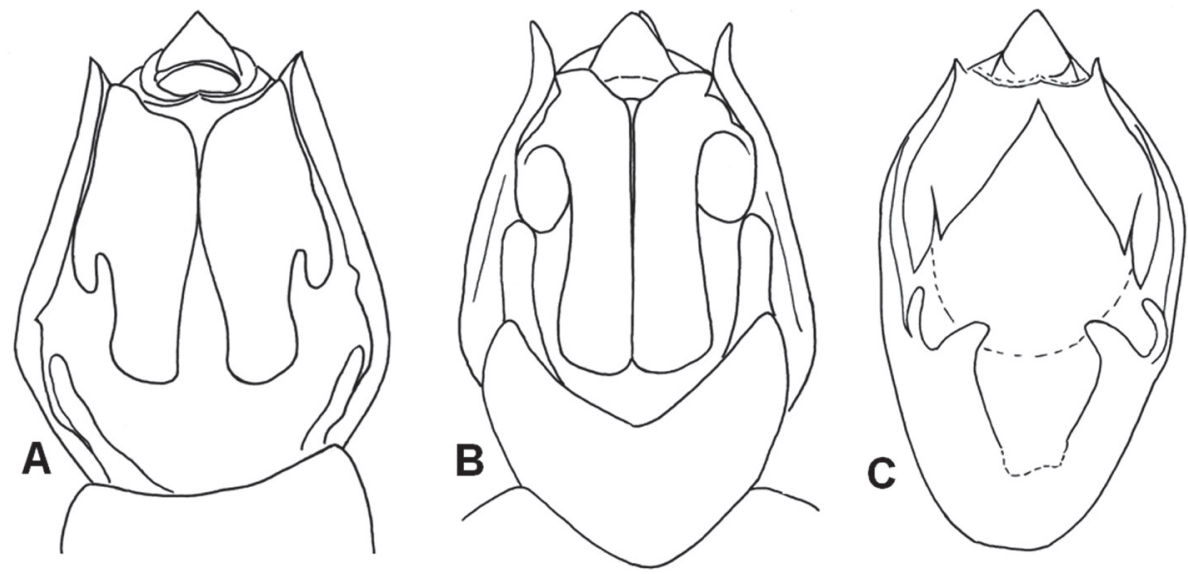

Figure 6. Male genital capsule of Semia species (ventral view): A Semia klapperichi B S. watanabei (after Lee and Hayashi 2003) C Semia spinosa sp. n.

dark brown; mid leg with coxa and femur pale yellow, tibia pale brown, apex of femur black, apex and base of tibia black, metatarsus and pretarsus dark brown, mesotarsus pale yellow; hind leg, with femur pale yellow, apex of femur dark brown, tibia pale 


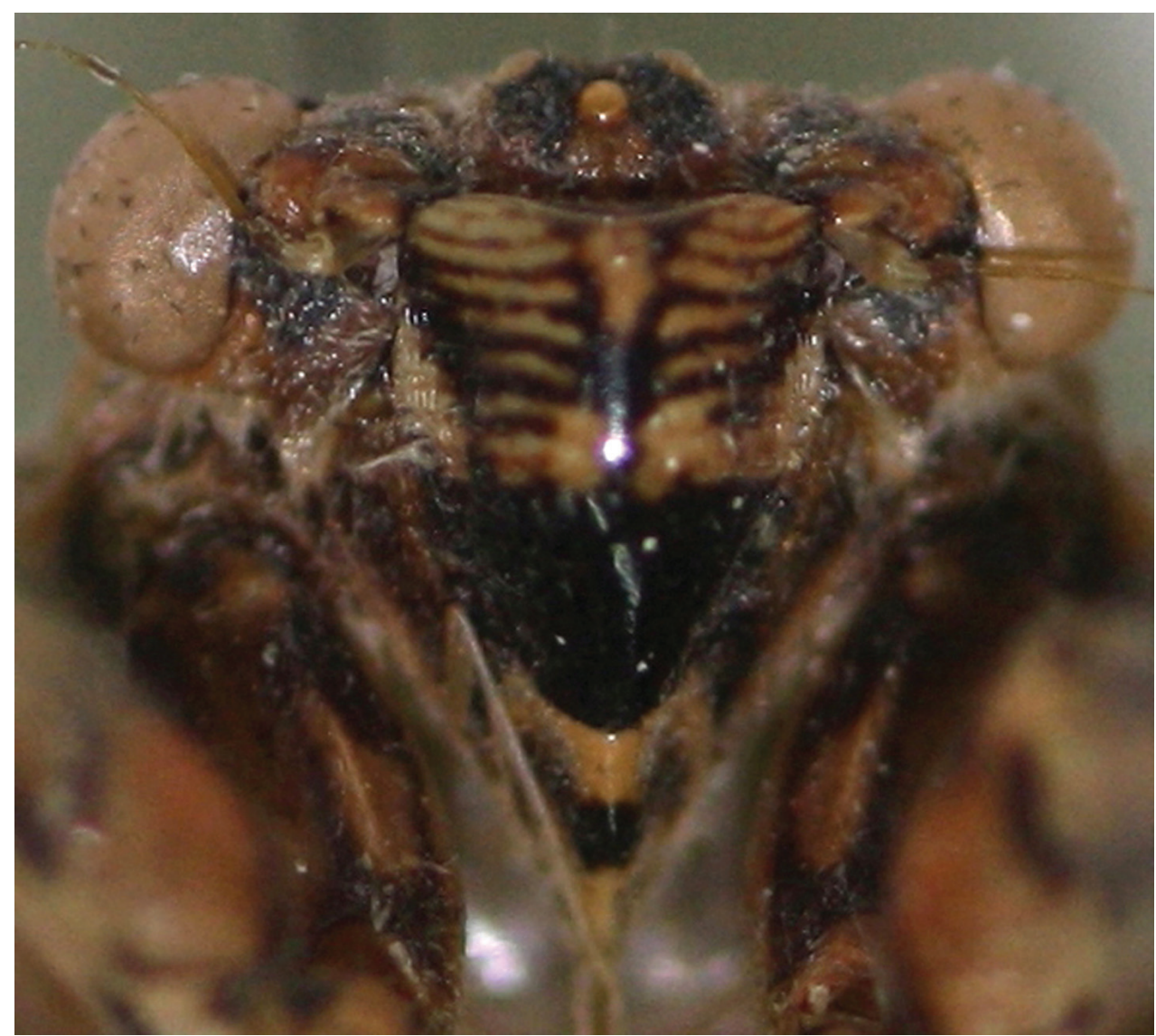

Figure 7. Postclypeus of Semia spinosa sp. n.

brown, base of tibia dark brown, tibial spur, tibial comb, and thumb of tibial comb dark brown.

Abdomen (Fig. 2B): pale greenish brown in dorsal view, with a longitudinal broad dark brown streak, tergites 3-7 with their lateral margins edged pale brown (Fig. 2A); pale brown in ventral view, anterior margin of sternites III - VI and sternites VII and VIII dark brown; epipleurites 3-6 lighter than sternites (Fig. 2B).

Operculum (Fig. 2B): pale yellow-green, short, transverse, and not reaching beyond anterior margin of sternite II.

Male genitalia (Figs 3A, B): Pygofer oblong in ventral view, lateral lobe of pygofer narrower than medial lobe, the latter triangular and prominent; dorsal beak acute and blackish brown; uncus brown, darker at apex of uncus lobes, the latter strongly divergent with two apical spines, medial spine shorter and acuter than lateral spine; Anal styles and anal tube dark brown. Aedeagus very slender.

Measurements in $\mathrm{mm}$ : (4 $\lesssim \precsim$ ): body length excluding wings: 27.1-29.0 (28.1); fore wing length: 31.0-32.6 (31.8); head width: 6.7-7.2 (7.0); pronotum width: 6.7$8.1(7.4)$. 


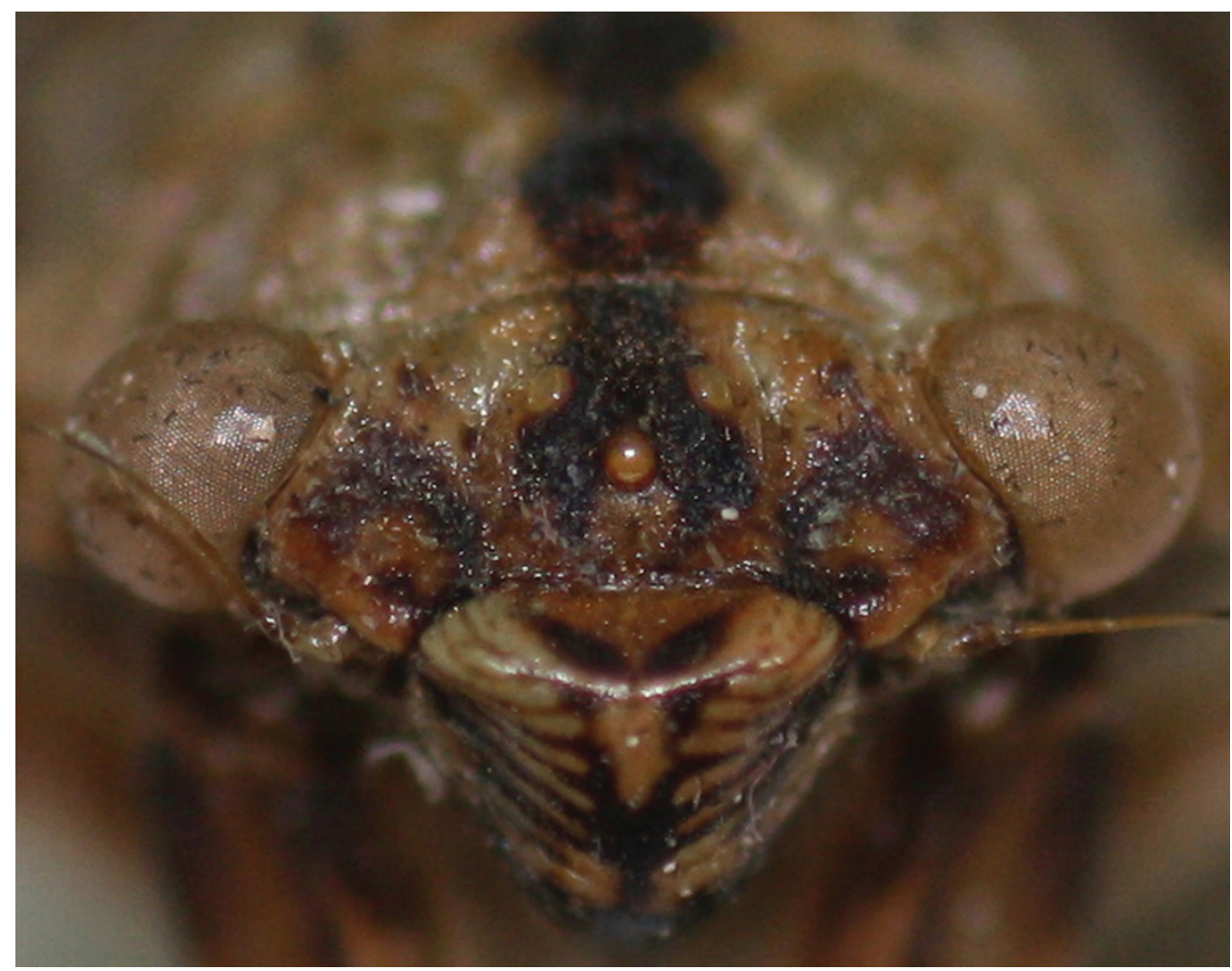

Figure 8. Dorsal part of the postclypeus of Semia spinosa sp. n.

Biology. This species was collected by sweeping during the daytime and by light trapping at night in virgin rainforest at an altitude between 100 to 150 meters.

Distribution. Vietnam (Dong Nai Province).

Remarks. S. spinosa is distinguishable from S. watanabei and S. klapperichi by the body size, which is shorter than $30 \mathrm{~mm}$ (in male) in $S$. spinosa and longer than $35 \mathrm{~mm}$ (in male) in S. watanabei and S. klapperichi, and from S. klapperichi it differs in the infuscations on the hind wings which lack spots along the ambient veins present in $S$. klapperichi (see Figs 4A, C). The new species also differs in the structure of the uncus which has the lobes strongly divergent with acute apical spines (see Figs 6A-C).

\section{Key to the species of the genus Semia (males)}

1 Body length $<30 \mathrm{~mm}$; abodomen with longitudinal broad brown band centrally (Fig. 2A); uncus lobes strongly divergent, each with two apical spines (Fig. 3A)

- $\quad$ Body length $>35 \mathrm{~mm}$; abodomen without longitudinal broad brown band centrally; uncus lobes not or weakly divergent without two apical spines .... 2 
2 Body length approximately $38 \mathrm{~mm}$; operculum with lateral margin not expanding beyond lateral margin of abdomen; tymbal cover very small, pale brown, with darker margin; tymbal mostly exposed in dorsal view; uncus lobes parallel (Fig. 6B)

S. watanabei

- $\quad$ Body length 40-45mm; operculum very wide, lateral margin expanding distinctly beyond lateral margin of abdomen; tymbal cover small slightly raised, brown without dark margin; tymbal slightly exposed in dorsal view; uncus lobes weakly divergent (Fig. 6A)

S. klapperichi

\section{Acknowledgments}

We thank Prof. Ta Huy Thinh, and Mr. Hoang Vu Tru (Institute of Ecology and Biological Resources, Hanoi) for assistance with field work sharing of specimens and data, Dr. Mick Webb (The Natural History Museum, London), Dr. Max Moulds (The Australian Museum), Dr. Hans Duffels (Netherlands Centre of Biodiversity), and Dr. Jerome Constant (Royal Belgian Institute of Natural Sciences) for their critical reading and valuable comments in improving the contents of the paper. We are grateful to Dr. Dirk Ahrens (Zoologisches Forschungsmuseum A. Koenig) for providing photographs of Semia klapperichi.

The first author is grateful for a scholarship for his $\mathrm{PhD}$ dissertation issued by the program of the National Chung Hsing University, Taiwan. We also thank Dr. Yves Samyn and Dr. Patrick Grootaert (Royal Belgian Institute of Natural Sciences) for grant support to the first author; the grant was issued by the capacity building Programme of the Belgian Global Taxonomic Initiative National Focal Point and runs with financial support from the Belgian Directorate-General for Development Cooperation.

The present study was partially supported by the National Foundation for Science and Technology Development (NAFOSTED-106.12.15.09), Vietnam, the International Foundation for Science (IFS-No D/5181-1), Sweden, and the Nagao Natural Environment Foundation, Japan.

\section{References}

Barbier Y, Rasmont P (2000) Carto Fauna-Flora 2.0. Guide d'utilisation. Université de Mons Hainaut, Mons, Belgique, 59 pp.

Chen CH (2007) A field guide to cicadas in Taiwan. Big Tree, Taiwan, 206 pp.

Distant WL (1913a) Contributions to a knowledge of Oriental Rhynchota. The Annals and Magazine of Natural History, (8), 12(69): 283-287.

Distant WL (1913b) On some recently received Rhynchota. The Annals and Magazine of Natural History, (8), 12(72): 556-563. 
Distant WL (1917a) The Homoptera of Indo-China. The Annals and Magazine of Natural History, (8), 19: 100-104. doi: 10.1080/00222931709486914

Distant WL (1917b) The Homoptera of Indo-China. The Annals and Magazine of Natural History, (8), 20, 319-325. doi: 10.1080/00222931709487014

Jacobi A (1944) Die Zikadenfauna der Proviz Fukien in Sudchina und ihre tiergeographischen Beziehungen. Muchen. Ent. Gesell. Mitt. 34: 5-66.

Lee YJ, Hayashi M (2003) Taxonomic review of Cicadidae (Hemiptera, Auchenorrhyncha) from Taiwan, part 2. Dundubiini (a part of Cicadina) with two new species. Insecta Koreana, 20: 359-392.

Lee YJ (2008) A checklist of Cicadidae (Insecta: Hemiptera) from Vietnam, with some taxonomic remarks. Zootaxa 1787: 1-27.

Matsumura S (1907) Die Cicadinen Japans. Annot. Zool. Japan. 6: 83-116.

Matsumura S (1917) A list of the Japanese and Formosan Cicadidae, with description of new species and genera. Transactions of the Sapporo Natural History Society 6: 186-212.

Moulds MS (2005) An appraisal of the higher classification of cicadas (Hemiptera: Cicadoidea) with special reference to the Australian fauna. Records of the Australian Museum 57: 375446. doi: 10.3853/j.0067-1975.57.2005.1447

Pham HT, Yang JT (2009) A contribution to the Cicadidae fauna of Vietnam (Hemiptera: Auchenorrhyncha), with one new species and twenty new records. Zootaxa 2249, 1-19.

Pham HT, Yang JT (2010) The genus Lemuriana Distant (Hemiptera: Cicadidae) from Vietnam, with a description of a new species. Oriental Insects, Vol. 44: 205-210. doi: 10.1080/00305316.2010.10417614

Pham HT, Ta HT, Yang JT (2010) A new cicada species (Hemiptera: Cicadidae), with a key to the species of the genus Euterpnosia Matsumura, 1917 from Vietnam. Zootaxa 2512: 63-68. 